\title{
PERILAKU KONSUMEN PRODUK LIPCREAM WARDAH (Studi Pada Mahasiswi Fakultas Ekonomi dan Bisnis Universitas Jember Kampus Bondowoso)
}

\author{
Zainuri; Septarina Prita Dania S; Isrofiatullaily Putri Giani \\ Universitas Jember
}

e-mail: zainuri.feb@unej.ac.id; yunania2006@yahoo.co.id; isrofiatullailyputri@gmail.com

\begin{abstract}
Women and cosmetics are inseparable, nowadays. This condition is also responded positively by cosmetic companies ranging from new product innovations to price promotions. The number of new products certainly has its assessment for regular customers. This research focuses on the Faculty of Economics and Business students at the University of Jember in Jember and Bondowoso. This study examines the effect of halal certificate, prices, and brand image on consumer loyalty to Wardah's lip cream products which have won top brand awards for the last three years. The study uses linear regression analysis and SPSS 25 software. The research findings reveal that the halal label variable does not affect consumer's loyalty. Price and brand image variables has significant positive effects on consumer's loyalty.
\end{abstract}

Keywords: brand image; customer loyalty; halal label; price

\section{Pendahuluan}

Penampilan telah menjadi prioritas utama bagi kaum wanita sebagai bentuk dan upaya agar lebih terlihat cantik, indah serta menarik dihadapan orang lain. Agar lebih terlihat cantik dan menarik salah satunya dapat dengan menggunakan kosmetik. Kosmetik merupakan sebuah produk yang digunakan pada tubuh untuk mempercantik, mengubah penampilan dan membersihkan yang digunakan pada kulit, rambut, wajah atau bibir. ${ }^{1}$ Saat ini, industri kosmetik mengalami pertumbuhan besar disebabkan karena meningkatnya obsesi kecantikan di kalangan wanita. Selain itu, semakin majunya teknologi informasi meningkatkan intensitas persaingan produk kosmetik, karena semakin banyaknya produk kosmetik yang dikenal konsumen. ${ }^{2}$ Kaum wanita sebagai konsumen utama yang memanfaat hasil produksi selalu memiliki pertimbangan dalam menentukan produk atau brand yang digunakan. Hal ini juga tercantum teori perilaku konsumen bahwa perilaku konsumen muncul ketika individu memiliki keinginan dalam memiliki atau memperoleh sesuatu. Pada ekonomi Islam, istilah perilaku konsumen selalu dikaitkan dengan ketentuan syariat Islam, salah satunya label halal pada produk. $^{3}$

Istilah halal sering dikaitkan tentang makanan dan minuman saja, akan tetapi halal tidak hanya mencakup kedua hal tersebut dan saat ini mulai popular dan diperluas pada bidangbidang lain, seperti pakaian, perbankan sampai kosmetik. Ishak mengatakan bahwa kosmetik

\footnotetext{
${ }^{1}$ S. Mohezar, et al, "Halal Cosmetics Adopotion Among Young Muslim Consumers in Malaysia Religisity Concern," GJAT, Volume 6, Nomor 1 (2016), 47.

${ }^{2}$ Suraiya Ishak, et al, "Cosmetics Purchase Behavior of Educated Millenial Muslim Females," Journal of Islamic Marketing, Volume 11, Nomor 5 (2019), 1058-1060.

${ }^{3}$ O. B. Saputi dan N. Huda, "Pengaruh Informasi Covid-19 Melaui Media Sosial Terhadap Perilaku Konsumen," Human Falah, Volume 7, Nomor 2 (2020), 62.
} 
halal berbeda dengan kosmetik biasa karena pada kosmetik halal tidak diperbolehkan mengandung produk babi dan turunannya, alkohol dan segala jenis bahan yang dilarang menurut Islam. ${ }^{4}$ Di Indonesia terdapat salah satu brand kosmetik yang terkenal akan image halalnya, yakni kosmetik Wardah. Kosmetik Wardah diproduksi oleh PT. Paragon Technology and Inovation pada tahun 1995 dan telah menghasilkan banyak produk kosmetik. Produk-produk kosmetik yang dihasilkan oleh Wardah, seperti foundation, bedak padat, facial wash, serum, mascara dan lipstik. Di antara produk kosmetik yang dihasilkan tersebut, yang paling mudah untuk diaplikasikan ialah lipstik. ${ }^{5}$ Adapun jenis lisptik yang dihasilkan oleh Wardah ada dua macam, yakni lipstik padat yang disebut lipstik dan lipstik cair/krim yang disebut lipcream. Lipcream masuk ke dalam kategori lipstik yang merupakan pewarna bibir di mana saat ini lipcream sedang banyak digemari oleh kaum perempuan, dari muda hingga dewasa. Lipcream lebih digemari ketimbang lipstik karena lipcream memiliki warna yang intens, tidak mudah transfer, lebih tahan lama, memiliki kemasan yang lucu dan unik.

Pada data Top Brand Award Indonesia tahun 2018 sampai 2020 dalam kategori lisptik, Wardah selalu konsisten menjadi top 1 dibandingkan dengan kompetitor sejenisnya.

Tabel 1.1. Indonesia Top Brand Award Lipstick Product 2018-2020

\begin{tabular}{|l|c|c|c|c|c|c|}
\hline \multirow{2}{*}{ Brand } & \multicolumn{2}{|c|}{ Tahun 2018} & \multicolumn{2}{c|}{ Tahun 2019} & \multicolumn{2}{c|}{ Tahun 2020 } \\
\cline { 2 - 7 } & TBI & TOP & TBI & TOP & TBI & TOP \\
\hline Wardah & $36.20 \%$ & TOP 1 & $33.40 \%$ & TOP 1 & $33.50 \%$ & TOP 1 \\
\hline Revlon & $10.70 \%$ & TOP 2 & $9.20 \%$ & - & $8.80 \%$ & - \\
\hline Maybeline & $7.60 \%$ & - & $4.50 \%$ & - & $4.10 \%$ & - \\
\hline Sariayu & $7.20 \%$ & - & - & - & - & - \\
\hline Pixy & - & - & $6.00 \%$ & - & $5.40 \%$ & - \\
\hline
\end{tabular}

Sumber : Topbrand awards. ${ }^{6}$

Alasan mengapa produk lipcream Wardah banyak diminati karena lipcream Wardah memiliki koleksi pilihan warna yang lengkap, dari kategori warna terang sampai warna nude. Lipcream Wardah juga memiliki tekstur isi yang creamy dalam sekali oles, ringan, warna yang intens dan lembut di bibir. Selain itu, harga yang ditawarkan oleh lipcream Wardah sangat terjangkau dan pas dengan kantong remaja serta memiliki kualitas yang baik. Dalam Top Brand Award Indoensia terdapat tiga kriteria penilaian dalam mengukur perfoma merek sebagai acuan. Pertama, mind share yang menunjukkan kekuatan merek dalam memposisikan diri dalam benak konsumen pada kategori terntu. Kedua, market share yang menunjukkan kekuatan merek dalam pasar dan berkaitan dengan perilaku konsumen dalam melakukan pembelian. Ketiga, commitment share yang menunjukkan kekuatan merek dalam mendorong pelanggan untuk melakukan pembelian ulang pada masa yang akan datang. ${ }^{7}$

\footnotetext{
${ }^{4}$ Suraiya Ishak, et al, "Cosmetics Purchase Behavior", 1058-1060.

Febri Amalia, "Alasan Wanita Harus Pakai Lipstik Sehari-hari." dalam https://lifestyle.okezone.com/read/2015/05/29/194/1157062/alasan-wanita-harus-pakai-lipstik-sehari-hari. Diakses pada 30 Januari 2021.

${ }^{6}$ https://www.topbrand-award.com/top-brand-index/?tbi_find=wardah. Diakses pada 20 November 2020.

${ }^{7}$ Ibid.
} 
Suatu perusahaan perlu memperhatikan apa saja yang mendasari pelanggan dalam memilih suatu produk hingga ia melakukan pembelian secara berulang dan muncul rasa loyalitas pelanggan. ${ }^{8}$ Tumbuhnya loyalitas pelanggan pada lipcream Wardah dapat timbul disebabkan oleh adanya label halal di mana halal menjadi branding pada kosmetik Wardah. Label halal pada kemasan produk, memberikan jaminan bahwa produk tersebut benar-benar halal dan aman untuk digunakan dan dikonsumsi serta terbebas dari segala sesuatu yang dilarang oleh Islam. Pencantuman label halal bagi produsen dapat membangun kepercayaan dan loyalitas pelanggan terhadap produk yang dipasarkan oleh produsen. ${ }^{9}$ Selain itu, penentuan harga yang dimiliki oleh produk lipcream Wardah pun juga dapat mempengaruhi pelanggan merasa loyal terhadap produk tersebut.

Penentuan harga menjadi daya tarik konsumen dalam menentukan pilihannya. Dengan nilai uang yang telah dikeluarkan diharapkan sebuah produk dapat memenuhi kebutuhan dan kepuasan konsumen, apabila dengan harga yang dikeluarkan konsumen merasa puas, maka konsumen akan berkeinginan untuk kembali membeli dan menggunakan produk yang sama. ${ }^{10}$ Brand image yang dimiliki oleh lipcream Wardah pun juga dapat mempengaruhi loyalitas pelanggannya. Image Wardah terkenal akan kampanye halalnya di mana hal tersebut dapat menjadi strategi perusahaan untuk menarik hati pelanggannya. Brand image yang dimiliki Wardah pun dinilai cukup menarik. Pelanggan menilai dan yakin bahwa produk tersebut memiliki kualitas yang baik pula. Setiap keputusan dalam membeli ulang sebuah produk dan menumbuhkan loyalitas pelanggan terhadap produk perusahaan, brand image akan menjadi patokan konsumen dalam memberikan keputusannya. ${ }^{11}$

Ada beberapa penelitian yang telah dilakukan oleh peneliti sebelumnya terkait beberapa faktor yang mempengaruhi loyalitas konsumen atas produk, di antaranya label halal, tingkat harga dan brand image. Fathurrahman dan Anggesti menyimpulkan bahwa harga dan label halal memiliki pengaruh positif dan signifikan terhadap keputusan pembelian kosmetik Safi. ${ }^{12}$ Hasil senada juga dipaparkan oleh Astuti dan Hakim yang menyimpulkan bahwa label halal memiliki pengaruh positif signifikan terhadap keputusan pembelian konsumen pada 212 Mart. ${ }^{13}$ Ariyono memaparkan bahwa labelisasi halal memiliki pengaruh positif signifikan terhadap loyalitas konsumen air mineral Azza di Lumajang. ${ }^{14}$ Hasil berbeda dipaparkan oleh Lubis yang menyatakan bahwa label halal tidak berpengaruh terhadap loyalitas konsumen. ${ }^{15}$ Yunaida menyatakan bahwa brand image memiliki pengaruh positif terhadap loyalitas

\footnotetext{
${ }^{8}$ Fandy Tjiptono, Strategi Pemasaran: Prinsip dan Penerapan (Yogyakarta: Penerbit ANDI, 2019), 86.

${ }^{9}$ Nur Hijriah., dan Saleh G., "Pengaruh Label Halal Pada Produk Kosmetik Terhadap Keputusan Pembelian," Jurnal Ilmu Komunikasi, Volume 3, Nomor 2 (2018), 50-75.

${ }^{10}$ F. Tjiptono, dan A. Diana, Pemasaran (Yogyakarta: Penerbit ANDI, 2019), 55.

11 Innocentius Bernato, et al, "The Influence of Brand Awareness, Brand Image, and Brand Trust on Brand Loyalty," Journal Manajemen, Volume 26, Nomor 3 (2020), 415.

12 A. Fathurrahman dan M. Anggesti, "Pengaruh Gaya Hidup, Label Halal dan Harga Terhadap Keputusan Pembelian Kosmetik (Studi Kasus Pada Produk Safi),” Jurnal Ekonomi Syariah, Volume 6, Nomor 2 (2021), 113-127.

13 Rini Astuti dan M. Ali Hakim, "Pengaruh Label Halal dan Ketersediaan Produk terhadap Keputusan Pembelian Konsumen di 212 Mart di Kota Medan," Maneggio: Jurnal Ilmiah Magister Manajemen, Volume 4, Nomor 1 (2021), 163.

14 Kurniawan Y. Ariyono, "Impact of Halal Product on Purchase Decision and Customer Satisfaction," International Journal of Accounting and Management Research (IJAMR), Volume 1, Nomor 2 (2020), $72-83$.

${ }^{15}$ N. I. Lubis, "Analisis Loyalitas Konsumen Produk Berlabel Halal,” Jurnal AL-QARDH, Volume 4, Nomor 1 (2019), 51-59.
} 
konsumen produk oli pelumas Evalube di Kota Langsa. ${ }^{16}$ Hasil serupa juga disampaikan Rusandy yang menyatakan adanya hubungan positif signifikan brand image terhadap loyalitas konsumen Rumah Makan Titin Trenggalek. ${ }^{17}$ Pangalila menyatakan bahwa harga produk berpengaruh signifikan terhadap loyalitas pelanggan pengguna aplikasi Gojek. ${ }^{18}$ Hasil berbeda dipaparkan oleh Bulan yang menyimpulkan bahwa harga memiliki pengaruh negatif terhadap loyalitas konsumen PT. Tiki Jalur Nugraha Ekakurir agen kota Langsa. Adanya perbedaan hasil pada penelitian sebelumnya mendorong adanya penelitian lanjutan mengenai loyalitas konsumen atas suatu produk. ${ }^{19}$

\section{Metode Penelitian}

Jenis penelitian ini menggunakan pendekatan kuantitatif dengan teknik pengumpulan data penelitian melalui metode survey kuisioner dengan bantuan google form. Objek penelitian ini adalah produk lipcream Wardah sedangkan subjek penelitian ini adalah Mahasiswi Fakultas Ekonomi dan Bisnis Universitas Jember Kampus Bondowoso angkatan 2017 sampai 2020 dan Mahasiswi Fakultas Ekonomi dan Bisnis Universitas Jember Kampus Bondowoso yang pernah melakukan lebih dari 1 kali pembelian.

Penelitian ini menggunakan uji metode suksesif interval yang digunakan untuk mentransformasikan data ordinal yang telah didapatkan melalui kuisioner ke data interval dengan bantuan Microsoft Excel 2010. Teknik analisis data menggunakan analisis regresi linier berganda dengan bantuan SPSS versi 25. Dengan tahapan uji asumsi klasik dan uji analisis linier berganda.

Variabel yang digunakan pada penelitian ini meliputi tiga variabel bebas dan satu variabel terikat yang terdiri atas label halal (X1), harga (X2), brand image (X3) dan loyalitas pelanggan (Y). Adapun indikator yang digunakan pada label halal (X1) yakni gambar, tulisan, menempel pada kemasan, bahan pertimbangan letak label pada kemasan. ${ }^{20}$ Indikator yang digunakan pada harga (X2) mengacu pada antara lain nilai (value), kesesuaian harga dengan kualitas, perbandingan harga dengan produk lain yang sejenis. ${ }^{21}$ Sedangkan indikator brand image (X3) antara lain lambang atau logo merek mudah diingat, merek mudah dikenali, merek yang terpercaya. ${ }^{22}$ Indikator dari loyalitas pelanggan (Y) antara lain kemauan untuk

\footnotetext{
16 E. Yunaida, "Pengaruh Brand Image (Citra Nerek) Terhadap Loyalitas Konsumen Produk Oil Pelumas Evalube di Kota Langsa," Jurnal Manajemen dan Keuangan, Volume 6, Nomor 2 (2017), 96.

17 Deby S. Rusandy, "Pengaruh Brand Image Terhadap Loyalitas Pelanggan yang Dimediasi Kepuasan Pelanggan pada Rumah Makan Titin Trenggalek," Jurnal Riset Inspirasi Manajemen dan Kewirausahaan, Volume 2, Nomor 1 (2018), 115.

${ }^{18}$ Paulus A. Pangalila, et al, "Pengaruh Kualitas Pelayanan dan Harga terhadap Loyalitas Pelanggan Pengguna Aplikasi Gojek,” Jurnal EMBA, Volume 6, Nomor 4 (2018), 2778-2787.

19 T. P. L. Bulan, "Pengaruh Kualitas Pelayanan dan Harga terhadap Loyalitas Konsumen Pada PT. Tiki Jalur Nugraha Ekakurir Agen Kota Langsa,” Jurnal Manajemen dan Keuangan, Volume 5, Nomor 2 (2016), 115.

${ }^{20}$ W. B. Utami, "Pengaruh Label Halal Terhadap Keputusan Membeli (Survei pada Pembeli Produk Kosmetik Wardah di Outlet Wardah Griya Muslim An-nisa Yogyakarta), (Skripsi--Universitas Islam Negeri Sunan Kalijaga, 2013), 7.

${ }^{21}$ M. R. Dinawan, “Analisis Faktor-Faktor yang Mempengaruhi Keputusan Pembelian (Studi Kasus pada Konsumen Yamaha Mio PT Harpindo Jaya Semarang)," Jurnal Sains Pemasaran Indonesia, Volume 9, Nomor 3 (2010), 342.

22 Ibid.
} 
menggunakan kembali, kesetiaan pelanggan dan rekomendasi positif. ${ }^{23}$ Adapun model persamaannya dapat dituliskan sebagai berikut:

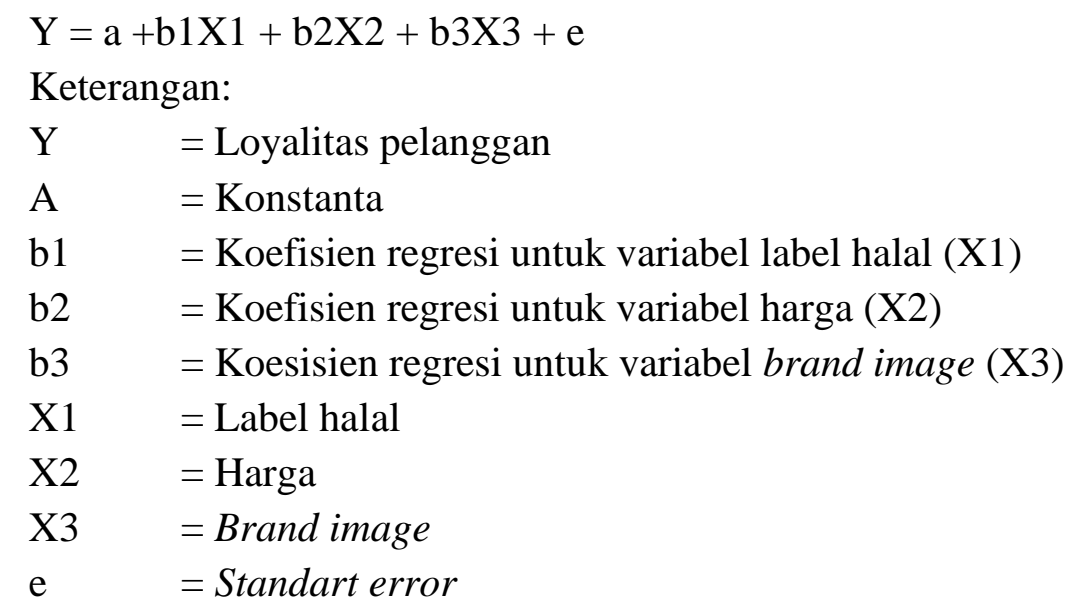

\section{Loyalitas Pelanggan}

Kotler dan Keller menyatakan bahwa loyalitas pelanggan didefinisikan sebagai komitmen yang dipegang teguh untuk membeli kembali atau menggunakan kembali produk atau layanan yang disukai di masa depan meskipun terdapat pengaruh situasi dan upaya pemasaran berpotensi menyebabkan peralihan. ${ }^{24}$ Pelanggan yang loyal memiliki tingkat kepuasan yang tinggi atau memiliki kesenangan dengan akan tetap membeli produk dan merek yang sama, merekomendasikan kepada orang lain secara positif dan menjadi pelanggan tetap. ${ }^{25}$ Tjiptono dan Diana pun mengungkapkan bahwa Loyalitas pelanggan tumbuh pada saat konsumen melakukan evaluasi terhadap produk atas keputusan pembelian yang telah dilakukan. Loyalitas terhadap brand perusahaan dapat terjadi ketika adanya pembelian secara berulang dan sering dari pelanggan atas merek dan produknya, pelanggan lebih memilih membeli merek dan produk yang sama daripada merek pesaing. ${ }^{26}$

Loyalitas pelanggan tidak akan tumbuh apabila pelanggan tidak atau belum melakukan pembelian terhadap suatu merek produk atau jasa terlebih dahulu. ${ }^{27}$ Adapun proses keputusan pembelian yang dapat menumbuhkan rasa loyalitas pelanggan, yaitu pertama, prapembelian yang terdiri atas identifikasi kebutuhan, mencari informasi dan evaluasi alternatif. Kedua, konsumsi di mana memutuskan untuk melakukan pembelian dan mengkonsumsi. Ketiga, evaluasi pascapembelian di mana konsumen mulai memberikan evaluasi terkait produk yang

\footnotetext{
${ }^{23}$ Andrea Denisa, dan Santoso S. B., "Analisis Pengaruh Kualitas Produk, Kualitas Layanan dan Citra Merek Terhadap Loyalitas Pelanggan (Studi Pada Klinik Kecantikan Cosmetics Semarang)," Diponegoro Journal of Management, Volume 5, Nomor 3 (2016), 6-7.

${ }^{24}$ P. Kotler dan K. Keller, Marketing Management, edisi 14 (United States of America: Courier/Kendallville, 2012), 118.

${ }^{25}$ Leon G. Schiffman dan J. Wisenblit, Consumer Behavior, edisi 11 (United States of America: Courier Kendallville, 2015), 185.

${ }^{26}$ Sena Odzemir, et al, "The Effect of Trust and Peer Influence on Coroporate Brand-Consumer Relationship and Consumer Loyalty,” Journal of Business Research, Volume 117, Nomor 37 (2020), 96.

27 Inka Janita Sembiring, et al, "Pengaruh Kualitas Produk dan Kualitas Pelayanan Terhadap Kepuasan Pelanggan dalam Membentuk Loyalitas Pelanggan (Studi Pada Pelanggan McDonalds MT. Haryono Malang), Jurnal Administrasi Bisnis, Volume 15, Nomor 1 (2014), 14-15.
} 
mereka pilih dan memutuskan apakah mereka merasa puas dan akan kembali membeli atau sebaliknya. Apabila pelanggan merasa puas dengan apa yang mereka dapatkan dan rasakan, maka mereka akan melakukan repeat order di masa yang akan datang dan dapat menjadi pelanggan yang loyal. Pengukuran tingkat loyalitas pelanggan akan dinilai menggunakan skala likert. Skala likert digunakan untuk mengukur sikap, pendapat, dan persepsi individu atau sekelompok mengenai sebuah fenomena. Skala likert memiliki gradasi dari paling positif dan paling negatif. ${ }^{28}$

\section{Label Halal}

Kotler dan Keller menyatakan bahwa label adalah tag sederhana atau grafik yang dirancang rumit yang merupakan bagian dari kemasan. ${ }^{29}$ Label dapat menjadi alat komunikasi pemasaran antara produsen dan konsumen karena mengandung beberapa informasi terkait produk tersebut. ${ }^{30}$ Sedangkan istilah halal merupakan segala sesuatu yang diijinkan atau diperbolehkan bagi umat Islam. Sebagai umat Islam diwajibkan untuk mengkonsumsi segala sesuatu yang halal. ${ }^{31}$ Arti label halal adalah tanda kehalalan akan suatu produk di mana label halal ini merupakan bentuk izin dari Majelis Ulama Indonesia (MUI) setelah dilakukannya sertifikasi halal dan dinyatakan halal atas sebuah produk dan selanjutnya sertifikat halal dapat diterbitkan.

Label halal pada kemasan produk dijadikan sebagai tanda bahwa produk telah diuji dan dinyatakan halal serta aman untuk dikonsumsi sehingga dapat memberikan kepastian hukum pada konsumen muslim khususnya untuk tidak perlu lagi merasa khawatir saat mengkonsumsi produk tersebut. Oleh sebab itu, adanya label halal pada sebuah kemasan produk dapat memberikan jaminan kepada konsumen saat melakukan pembelian bahwa produk yang mereka gunakan benar-benar aman dan halal sehingga terbebas dari dosa dan menghadirkan ketenangan saat mengkonsumsinya, selain itu dapat dijadikan bukti bahwa produk tersebut terjamin akan kebersihan, keamanan dan kualitasnya karena telah melalui proses sertifikasi halal. ${ }^{32}$

\section{Harga}

Harga menjadi faktor yang sering diperhatikan oleh konsumen sebelum memutuskan untuk membeli suatu produk. ${ }^{33}$ Kotler dan Amstrong mengungkapkan bahwa harga ialah jumlah nilai yang diberikan keada pelanggan untuk mendapatkan keuntungan, memiliki dan

\footnotetext{
${ }^{28}$ Sugiyono, Metode Penelitian Kuantitatif, Kualitatif, dan R\&D (Bandung: CV. Alfabeta, 2013), 52.

${ }^{29}$ P. Kotler dan K. Keller, Marketing Management, 119.

${ }^{30}$ D. Celia Henley, et al, "Label Design: Impact on Millenials' Perceptions of Wine," International Journal of Wine Bussines Research, Volume 20, Nomor 1 (2010), 8.

${ }^{31}$ Ibid.

${ }^{32}$ Y. A. Aziz dan N. V. Chock, "The Role of Halal Awareness, Halal Certification, and Marketing Components in Determining Halal Purchase Intention Among Non-Muslim in Malaysia: A Structural Equation Modeling Approach," Journal of International Food \& Agrbusiness Marketing, Volume 25, Nomor 1 (2013), 1-23.

Lihat juga Haruna Jaiyeoba, et al, "Halal Certification Mark, Brand Quality and Awareness Do They Influence Buying Decisions of Nigerian Consumers?” Journal of Islamic Marketing, Volume 11, Nomor 6 (2019), 152.

${ }^{33}$ Sudaryanto, et al, "Impact of Culture, Brand Image and Price on Buying Decisions: Evidence from East Java, Indonesia,” Journal Innovative Marketing, Volume 17, Nomor 1 (2021), 130-133.
} 
menggunakan suatu produk atau layanan. ${ }^{34}$ Harga berperan sangat krusial dalam pemasaran di mana peran harga dapat mempengaruhi tingkat permintaan, profitabilitas dan persepsi konsumen. Konsumen mempersepsikan harga sebagai suatu nilai yang terkandung dalam suatu harga/nilai yang berhubungan dengan manfaat dan kepemilikan atau kepenggunaan produk atau jasa. ${ }^{35}$

Harga menjadi salah satu indikator nilai yang berhubungan dengan manfaat. ${ }^{36}$ Kebanyakan pelanggan memandang harga sebagai indikator dari kualitas produk. ${ }^{37}$ Pada tingkat harga tertentu, jika manfaat yang dirasakan oleh konsumen memuaskan, maka nilai dari satu produk pun akan meningkat. ${ }^{38}$ Oleh sebab itu, perusahaan dituntut untuk selalu memberikan asumsi baik kepada konsumen melalui harga agar konsumen merasa puas dan menerima produk yang dihasilkan dengan baik sehingga akan menimbulkan rasa ingin membeli kembali di waktu yang akan datang.

\section{Brand Image}

Menurut Kotler dan Keller, brand image merupakan persepsi dan keyakinan yang dipegang oleh konsumen yang dicerminkan asosiasi tertanam dalam ingatan pelanggan, yang selalu diingat pertama kali dan tertanam dibenaknya. ${ }^{39}$ Brand image memiliki nilai finansial karena dapat menciptkan aset yang sangat berharga di benak dan hati pelanggan. ${ }^{40}$ Brand image sendiri dapat terbentuk secara langsung melalui pengalaman pelanggan dengan produk, merek, dan situasi pemakaian. Selain itu dapat juga terbentuk secara tidak langsung melalui iklan dalam berbagai media dan komunikasi yang dilakukan secara gethok tular.

Brand image akan memiliki pengaruh langsung terhadap tingginya minat beli dan berkontribusi untuk menumbuhkan kepercayaan pelanggan terhadap suatu merek produk. Shamma mengungkapkan bahwa dengan brand image yang baik akan dapat menciptakan ketertarikan konsumen untuk melakukan pembelian. ${ }^{41}$ Oleh sebab itu, pentingnya suatu perusahaan atau produk memiliki image yang baik dan positif di mata pelanggan karena dengan demikian akan mendatangkan banyak manfaat seperti kepuasan pelanggan, tumbuhnya loyalitas pada diri pelanggan dan kesediaan pelanggan untuk merekomendasikan merek kepada orang lain sehingga perusahaan akan mempereoleh banyak keuntungan yang didapatkan.

\footnotetext{
${ }^{34}$ P. Kotler dan G. Amstrong, Principles of Marketing, edisi 14 (New Jersey: Pearson Education, 2014), 193.

${ }^{35}$ Ibid.

36 Harti dan M. I. Iffathurjannah, "Pengaruh Kemanan Makanan, Harga dan Rasa Terhadap Keputusan Pembelian,” Jurnal Akuntanbel, Volume 18, Nomor 2 (2021), 237.

${ }^{37}$ P. Kotler dan K. Keller, Marketing Management, 119.

38 A. Habibah, "Analisis Labelisasi Halal, Harga dan Rasa terhadap Keputusan Pembelian Konsumen pada Produk Mie,” Jurnal QIEMA, Volume 6, Nomor 1 (2020), 79.

${ }^{39}$ P. Kotler dan K. Keller, Marketing Management, 120.

${ }^{40}$ J. N. Kapferer, Strategic Brand Management, edisi 5 (London: Kogan Page, 2012), 172.

${ }^{41}$ H. M. Shamma dan S. S. Hassan, "Impact of CSR Perception on Brand Image, Brand Attitude, and Buying Willingness: A Study of a Global Café," International Journal of Marketing Studies, Volume 6, Nomor 6 (2014), 41-56.
} 


\section{Uji Validitas}

Uji validitas merupakan dasar pengambilan keputusan apabila variabel dapat dikatakan valid pada taraf signifikan 5\% apabila nilai $r$ hitung lebih besar dari $r$ tabel ( $r_{\text {hitung }}>r_{\text {tabel }}$ ) dan apabila variabel dapat dikatakan tidak valid pada taraf signifikan 5\% apabila nilai $\mathrm{r}$ hitung lebih kecil dari $\mathrm{r}$ tabel ( $\mathrm{r}$ hitung $<\mathrm{r}$ tabel). Uji validitas dalam penelitian ini memuat 14 butir pernyataan dan masing-masing pernyataan menunjukkan nilai $r$ hitung $>r$ tabel $(0,235)$.

\section{Uji Reabilitas}

Uji reliabilitas bertujuan untuk menentukan apakah variabel reliabel atau tidak jika reliabilitas variabel > 0,6. Dalam penelitian ini, pada variabel X1, X2, dan X3 masing-masing memiliki nilai cronbach alpha lebih besar dari koefisien alpha 0,6. Sehingga dapat ditarik kesimpulan bahwa semua pernyataan kuisioner dinyatakan valid dan reliabel untuk digunakan dalam penelitian.

\section{Uji Normalitas}

Uji normalitas menggunakan metode Kolmogrov-Smirnov, diketahui nilai Asymp. Sig (2-tailed) atau nilai signifikansi $(\alpha)$ sebesar 0,200 di mana lebih besar dari nilai signifikansi ( $\alpha$ ) 0,05 sehingga sebaran data dinyatakan berdistribusi normal.

\section{Uji Heterokedatisitas}

Penelitian ini menggunakan uji glejse sebagai uji heteroskedastisitas, menghasilkan kesimpulan bahwa tidak terjadi heteroskedastisitas karena nilai signifikan $>0,05$. Selanjutnya pengolahan data melalui analisis regsi linier berganda dilakukan menggunakan uji F dan uji T.

\section{Uji Multikolinearitas}

Dalam uji multikolineritas dalam penelitian ini dinyatakan tidak terjadi gejala multikolinieritas, di mana masing-masing variabel independen nilai VIF $<10$ dan nilai tolerance $>0,1$.

\section{Gambaran Umum Subjek Penelitian}

Dengan kriteria yang ditentukan pada penentuan responden diperoleh total 70 responden, karakteristik data yang diperoleh sebagai berikut:

1. Program studi

Data tabel 1.2. yaitu karakteristik responden berdasarkan program studi di Fakultas Ekonomi dan Bisnis berjulmlah 70 responden dengan rincian pada Program Studi Ekonomi Syariah terdapat 48 responden atau 68,8\% sedangkan pada Program Studi Akuntasi terdapat 22 responden atau 31,4\%.

Tabel 1.2. Karakteristik Responden Berdasarkan Program Studi

\begin{tabular}{|l|c|c|}
\hline Program Studi & Jumlah & Persentase \% \\
\hline Ekonomi syariah & 48 & $68,8 \%$ \\
\hline Akuntansi & 22 & $31,4 \%$ \\
\hline Total & $\mathbf{7 0}$ & $\mathbf{1 0 0 \%}$ \\
\hline
\end{tabular}


2. Tahun angkatan

Dari 70 total responden penelitian ini terdiri dari empat angkatan mahasiswa, yaitu angkatan tahun 2017, angkatan tahun 2018, angkatan tahun 2019 dan angkatan tahun 2020. Pada angkatan tahun 2019 terdapat 25 responden dengan 35,7\%, sedangkan pada angkatan tahun 2018 terdapat 18 responden deng 25,75\%. Pada angkatan tahun 2019 terdapat 14 responden dengan 20,0\% dan angkatan tahun 2020 dengan 13 responden atau $18,6 \%$.

Tabel 1.3. Karakteristik Responden Berdasarkan Tahun Angkatan

\begin{tabular}{|c|c|c|}
\hline Tahun & Jumlah & Persentase \% \\
\hline 2017 & 25 & $35,7 \%$ \\
\hline 2018 & 18 & 25,75 \\
\hline 2019 & 14 & $20,0 \%$ \\
\hline 2020 & 13 & $18,6 \%$ \\
\hline Total & 70 & $100 \%$ \\
\hline
\end{tabular}

3. Agama

Karakteristik responden berdasarkan agama sebanyak 70 responden yaitu beragama Islam dengan prosentase $100 \%$.

4. Jumlah pembelian

Karakteristik responden berdasarkan jumlah pembelian sebanyak 70 responden dengan jumlah pembelian lebih dari 1 kali dengan $100 \%$.

\section{Hasil dan Pembahasan}

Analisis Regresi Linear

Hasil uji regresi linier pada penelitian ini disajikan pada tabel sebagai berikut:

Tabel 1.4. Hasil Regresi Linier Berganda

\begin{tabular}{|l|c|c|}
\hline \multicolumn{1}{|c|}{ Model } & $\begin{array}{c}\text { Unstandardized } \\
\text { Coefficients }\end{array}$ & Std. Error \\
\hline (Constant) & 2,220 & 1,518 \\
\hline Label halal & 0,067 & 0,070 \\
\hline Harga & 0,411 & 0,126 \\
\hline Brand image & 0,275 & 0,131 \\
\hline
\end{tabular}

Berdasarkan tabel 1.4. di atas diketahui hasil persamaan regresi linier adalah $\mathrm{Y}=2,220$ $+0,067$ label halal $(\mathrm{X} 1)+0,411$ harga $(\mathrm{X} 2)+0,275$ brand image $(\mathrm{X} 3)+\mathrm{e}$.

Diperoleh hasil persamaan regresi di atas bahwa konstanta bernilai positif, yakni sebesar 2,220. Artinya apabila tidak ada variabel label halal, harga, brand image maka loyalitas pelanggan sebesar 2,220. Koefisien label halal bernilai positif, yakni sebesar 0,067. Artinya adanya kenaikan satu unit pada label halal, maka akan terjadi kenaikan sebesar 0,067. Begitu juga sebaliknya, adanya penurunan satu unit label halal, maka akan terjadi penurunan sebesar 0,067 pada loyalitas pelanggan. Koefisien harga bernilai positif, yakni sebesar 0,411 . Artinya 
adanya kenaikan satu unit pada harga, maka akan terjadi penurunan sebesar 0,411. Begitu juga sebaliknya, adanya penurunan satu unit harga, maka akan terjadi kenaikan sebesar 0,411 pada loyalitas pelanggan. Sedangkan koefisien brand image bernilai positif yakni sebesar 0,275 . Artinya adanya kenaikan satu unit pada brand image, maka akan terjadi kenaikan sebesar 0,275. Begitu juga sebaliknya, adanya penurunan satu unit brand image, maka akan terjadi penurunan sebesar 0,275 pada loyalitas pelanggan.

\section{Uji F (Simultan)}

Selanjutnya peneliti melakukan uji $\mathrm{F}$ untuk mengetahui variabel independen berpengaruh signifikan terhadap variabel dependen. ${ }^{42}$ Berikut hasil uji $\mathrm{F}$ di bawah ini:

Tabel 1.5. Hasil Uji F (Simultan)

\begin{tabular}{|l|c|c|c|c|c|}
\hline \multicolumn{1}{|c|}{ Model } & Sum of Squares & Df & $\begin{array}{c}\text { Mean } \\
\text { Square }\end{array}$ & F & Sig. \\
\hline Regression & 149,760 & 3 & 49,920 & 12,944 & 0.0000 \\
\hline Residual & 254,529 & 66 & 3,857 & & \\
\hline Total & $\mathbf{4 0 4 , 2 8 9}$ & $\mathbf{6 9}$ & & & \\
\hline
\end{tabular}

Berdasarkan tabel 1.5. di atas, ditemukan nilai $F$ tabel sebesar 2,744 sehingga dapat ditarik kesimpulan bahwa F hitung > F table, yakni 12,944 > 2,744. Artinya, variabel X1, X2, dan X3 secara simultan berpengaruh positif dan signifikan terhadap loyalitas pelanggan.

\section{Uji T (Parsial)}

Tahapan selanjutnya yakni uji t untuk menguji pengaruh variabel label halal (X1), harga (X2), brand image (X3) terhadap loyalitas pelanggan (Y) secara parsial. Berikut hasil uji t di bawah ini:

Tabel 1.6. Hasil Uji T (Parsial)

\begin{tabular}{|l|c|c|c|c|c|}
\hline \multicolumn{1}{|c|}{ Variabel } & T hitung & t tabel & Sig. & Alpa & Keterangan \\
\hline Label halal (X1) & 0,959 & 1,997 & 0,341 & 0,05 & H0 diterima \\
\hline Harga (X2) & 3,265 & 1,997 & 0,002 & 0,05 & H0 ditolak \\
\hline Brand Image (X3) & 2,095 & 1,997 & 0,040 & 0,05 & H0 ditolak \\
\hline
\end{tabular}

\section{Pengaruh Label Halal Terhadap Loyalitas Pelanggan}

Dapat diketahui nilai $\mathrm{t}$ hitung dari label halal (X1) sebesar 0,959 di mana artinya nilai tersebut kurang dari t tabel, yaitu 1,997 dan nilai signifikansi dari variabel label halal terhadap loyalitas pelanggan adalah sebesar 0,341 >0,05, sehingga dapat ditarik kesimpulan bahwa H1 ditolak. Artinya variabel label halal tidak terdapat pengaruh positif dan signifikan terhadap loyalitas pelanggan lipcream Wardah. Hal ini menunjukkan bahwa dalam loyalitas pelanggan lipcream Wardah pada mahasiswi Fakultas Ekonomi dan Bisnis di Universitas Jember

\footnotetext{
${ }^{42}$ Duwi Priyatno, SPSS Panduan Mudah Olah Data Bagi Mahasiswa dan Umum (Yogyakarta: Penerbit ANDI, 2018), 82 .
} 
Kampus Bondowoso dalam melakukan repeat order di masa yang akan datang tidak perlu lagi mempertimbangkan adanya label halal pada kemasan lipcream Wardah. Karena di saat mereka melakukan pembelian pertama kali, mereka telah memastikan di awal bahwa lipcream Wardah benar-benar terjamin kehalalannya dengan memperhatikan adanya label halal di awal pembeliannya.

Temuan penelitian ini sudah sejalan dengan konsep teori loyalitas pelanggan menurut Kotler yang menurutnya merupakan sebuah komitmen pelanggan untuk membeli atau menggunakan kembali produk atau layanan yang disukai di masa yang akan datang. Bagi pelanggan baru tentunya keberadaan label halal pada suatu produk tentu mempengaruhi keputusan pembelian tetapi bagi pelanggan yang sudah melakukan pembelian lebih dari 1 kali tentunya ada keputusan tersendiri jika dilakukan pembelian berulang-ulang kali maka produk terkait sudah memuaskan dan sesuai keinginan pelanggan sehingga ada tidaknya label halal tidak menjadi pertimbangan. Hasil penelitian ini juga sejalan dengan hasil temuan Dora dan Faritzal yang mengungkapkan bahwa label halal tidak akan mempengaruhi loyalitas konsumen produk kosmetik dengan pembelian lebih dari 1 kali. ${ }^{43}$ Di sisi lain, hasil penelitian ini bertentangan dengan temuan Bulan dan Wahyurini yang menghasilkan kesimpulan bahwa label halal memiliki pengaruh positif dan signifikan terhadap keputusan pembelian.

\section{Pengaruh Harga Terhadap Loyalitas Pelanggan}

Diketahui nilai t hitung dari harga (X2) sebesar 3,265 di mana artinya nilai tersebut lebih dari t tabel, yaitu 1,997 dan nilai signifikansi dari variabel harga terhadap loyalitas pelanggan adalah sebesar 0,002 < 0,05, sehingga dapat ditarik kesimpulan bahwa $\mathrm{H} 2$ diterima. Artinya variabel harga terdapat pengaruh positif dan signifikan terhadap loyalitas pelanggan lipcream Wardah. Hasil tersebut membuktikan bahwa persepsi pelanggan terhadap harga lipcream Wardah dapat mempengaruhi loyalitas pelanggan pada mahasiswi Fakultas Ekonomi dan Bisnis Universitas Jember Kampus Bondowoso.

Pelanggan lipcream Wardah cenderung melihat dari segi harga dengan menilai apakah harga yang ditawarkan dapat memberikan manfaat, dapat memberikan keuntungan bagi pelanggan, dan apakah sesuai dengan kebutuhan dan keinginan dari pelanggan. Apabila dengan harga yang mereka telah bayarkan sesuai dengan keinginan, ekspetasi dan kebutuhan mereka maka mahasiswi mahasiswi Fakultas Ekonomi dan Bisnis di Universitas Jember Kampus Bondowoso akan melakukan pembelian secara berulang di masa yang akan datang dan loyalitas pelanggan tumbuh pada diri mereka. Namun apabila dengan harga yang mereka bayarkan tidak sesuai dengan keinginan dan ekspetasi dari pelanggan seperti harga yang tidak sepedan dengan kualitas yang didapatkan, harga tidak sepadan dengan manfaat yang dirasakan dan harga yang lebih tinggi dari produk sejenis dengan merek pesaingnya, maka mahasiswi Fakultas Ekonomi dan Bisnis di Universitas Jember Kampus Bondowoso akan beralih dan meninggalkan produk lipcream Wardah dan rasa loyal pada diri pelanggan tidak akan tumbuh.

\footnotetext{
${ }^{43}$ Y. M. Dora dan A. Faritzal, "The Use of Halal to Improve the Consumer Loyalty of Cosmetik Products in Bandung City Indonesia," International Journal of Psychosocia Rehabiliation, Volume 24, Nomor 2 (2020), 3308-3313.
} 
Temuan hasil penelitian ini sejalan dengan teori Peter dan Olson mengenai presepsi harga bahwa penetapan harga yang cukup menarik diimbangi dengan tingkat kepuasan atas produk serta kualitas produk akan meningkatan loyalitas serta keputusan pembelian oleh konsumen. ${ }^{44}$ Di samping itu, hasil penelitian ini sejalan dengan temuan penelitian Fathurrahman dan Anggesti yang menyimpulkan bahwa harga dan label halal memiliki pengaruh positif dan signifikan terhadap keputusan pembelian kosmetik Safi, serta penemuan ini bertentangan dengan hasil temuan Bulan yang menyimpulkan bahwa harga memiliki pengaruh negatif terhadap loyalitas konsumen PT. Tiki Jalur Nugraha Ekakurir agen kota Langsa. Adanya perbedaan hasil pada penelitian sebelumnya mendorong adanya penelitian lanjutan mengenai loyalitas konsumen atas suatu produk.

\section{Pengaruh Brand Image Terhadap Loyalitas Pelanggan}

Diketahui nilai t hitung dari brand image (X3) sebesar 2,095 di mana artinya nilai tersebut lebih dari t table, yaitu 1,997 dan nilai signifikansi dari variabel brand image terhadap loyalitas pelanggan adalah sebesar 0,040 < 0,05, sehingga dapat ditarik kesimpulan bahwa H3 diterima. Artinya variabel brand image terdapat pengaruh positif dan signifikan terhadap loyalitas pelanggan lipcream Wardah. Hal ini membuktikan bahwa mahasiswi Fakultas Ekonomi dan Bisnis di Universitas Jember Kampus Bondowoso sangat memperhatikan brand image yang dimiliki oleh lipcream Wardah. Di mana berdasarkan data yang diperoleh melalui kuisioner membuktikan bahwa logo merek produk lipcream Wardah telah melekat dibenaknya, mereka akan dengan mudah menjumpai dan mengenali produk lipcream Wardah meski terdapat produk sejenis dengan merek pesaing, selain itu Mahasiswi Fakultas Ekonomi dan Bisnis di Universitas Jember Kampus Bondowoso percaya bahwa lipcream Wardah benar-benar aman, halal, dan memiliki kualitas yang baik.

Dengan demikian dapat diketahui semakin baik brand image yang dimiliki oleh lipcream Wardah, maka semakin tinggi loyalitas pelanggan dalam membeli dan menggunakan lipcream Wardah kembali. Begitupun sebaliknya, semakin buruk brand image yang dimiliki lipcream Wardah, maka semakin rendah tingkat loyalitas pelanggan dalam membeli dan menggunakan kembali lipcream Wardah. Brand image yang baik dan positif di mata pelanggan diyakini akan mendatangkan berbagai manfaat keuntungan bagi perusahaan, seperti kepuasan pelanggan, menumbuhkan loyalitas dalam diri pelanggan, pelanggan bersedia membayar harga premium, pelanggan bersedia untuk merekomendasikan kepada orang lain dan pelanggan dapat menignkatkan jumlah pembeliannya. Oleh sebab itu apabila perusahaan ingin mendapatkan keuntungan dan menumbuhkan loyalitas pelanggan dari diri pelanggan perlu memperhatikan dengan baik brand image yang dimilikinya supaya pelanggan dapat tertarik terhadap produk yang dihasilkannya.

Hasil ini sejalan dengan penelitian yang telah dilakukan oleh $\operatorname{Rahman}^{45}$ yang menghasilkan kesimpulan bahwa citra merek (brand image) berpengaruh positif dan

\footnotetext{
${ }^{44}$ Nurul F. A. dan E. Soliha, "Kualitas Produk, Citra Merek dan Persepsi Harga terhadap Proses Keputusan Pembelian Konsumen Motor Matic Honda," Jurnal Manajemen Teori dan Terapan, Volume 10, Nomor 1 (2017), 59.

${ }^{45}$ Abd Rahman Azmawani, et al, "Consumer and Halal Cosmetic Product: Knowledge, Religiosity, Attitude and Intention.” Journal of Islamic Marketing, Volume 6, Nomor 1 (2015), 149.
} 
signifikan terhadap keputusan pembelian yang dilakukan oleh pelanggan. Hasil temuan ini sejalan dengan teori Kotler dan Keller yang menyatakan bahwa kenaikan brand image akan meningkatan loyalitas konsumen yang berpengaruh peningkatan pembelian atas produk terkait. ${ }^{46}$ Hasil penelitian ini bertentangan dengan temuan Firanazulah yang menyatakan bahwa brand image tidak memiliki pengaruh terhadap loyalitas konsumen. ${ }^{47}$

\section{Kesimpulan}

Berdasarkan hasil penelitian di atas, maka dapat ditarik kesimpulan bahwa label halal dengan variabel loyalitas pelanggan secara parsial tidak berpengaruh positif dan signifikan terhadap loyalitas pelanggan lipcream Wardah. Tidak berpengaruh positif tersebut menunjukkan bahwa label halal pada kemasan produk lipcream Wardah tidak menjadi penentu dalam menumbuhkan rasa loyalitas pelanggan lipcream Wardah pada mahasiswi Fakultas Ekonomi dan Bisnis di Universitas Jember Kampus Bondowoso. Sedangkan harga dengan variabel loyalitas pelanggan diperoleh kesimpulan bahwa harga secara parsial berpengaruh positif dan signifikan terhadap loyalitas pelanggan lipcream Wardah. Berpengaruh secara positif dan signifikan tersebut menunjukkan bahwa semakin sesuai harga yang ditawarkan dengan keinginan dan kebutuhan pelanggan, maka rasa loyalitas pelanggan produk lipcream Wardah akan tumbuh pada mahasiswi Fakultas Ekonomi dan Bisnis di Universitas Jember Kampus Bondowoso. Sedangkan variabel brand image terhadap loyalitas pelanggan, diperoleh kesimpulan bahwa brand image secara parsial berpengaruh positif dan signifikan terhadap loyalitas pelanggan lipcream Wardah. Berpengaruh secara positif dan signifikan tersebut menunjukkan bahwa semakin baik brand image yang ditampilkan oleh lipcream Wardah, maka akan meningkatkan dan menumbuhkan rasa loyalitas pelanggan lipcream Wardah pada mahasiswi Fakultas Ekonomi dan Bisnis di Universitas Jember Kampus Bondowoso.

\section{Daftar Rujukan}

A, Nurul. F. dan E. Soliha. "Kualitas Produk, Citra Merek dan Persepsi Harga terhadap Proses Keputusan Pembelian Konsumen Motor Matic Honda." Jurnal Manajemen Teori dan Terapan, Volume 10, Nomor 1 (2017).

Amalia, Febri. "Alasan Wanita Harus Pakai Lipstik Sehari-hari." dalam https://lifestyle.okezone.com/read/2015/05/29/194/1157062/alasan-wanita-harus-pakailipstik-sehari-hari. Diakses pada tanggal 30 Januari 2021.

Amstrong, G. Principles of Marketing, edisi 14. New Jersey: Pearson Education, 2011.

Ariyono, Kurniawan Y. "Impact of Halal Product on Purchase Decision and Customer Satisfaction." International Journal of Accounting and Management Research (IJAMR), Volume 1, Nomor 2 (2020).

Astuti, Rini dan M. Ali Hakim. "Pengaruh Label Halal dan Ketersediaan Produk terhadap Keputusan Pembelian Konsumen di 212 Mart di Kota Medan.” Maneggio: Jurnal

\footnotetext{
46 E. N. Jannah, et al, "Pengaruh Kualitas Layanan dan Brand Image Terhadap Loyalitas Melalui Kepuasan Pelanggan Matahari Department Store di Jember," Seminar Nasional Manajemen dan Bisnis Ke-3 (2018).

${ }^{47}$ Firanazulah, et al, "Citra Merek dan Kualitas Produk Terhadap Loyalitas Konsumen," Akuntabel, Volume 18, Nomor 1 (2021), 1-9.
} 
Ilmiah Magister Manajemen, Volume 4, Nomor 1 (2021).

Aziz, Y. A dan N. V. Chock. "The Role of Halal Awareness, Halal Certification, and Marketing Components in Determining Halal Purchase Intention Among Non-Muslim in Malaysia: A Structural Equation Modeling Approach.” Journal of International Food \& Agrbusiness Marketing, Volume 25, Nomor 1 (2013).

Azmawani, Abd Rahman, et al. "Consumer and Halal Cosmetic Product: Knowledge, Religiosity, Attitude and Intention.” Journal of Islamic Marketing, Volume 6, Nomor 1 (2015).

Bernato, Innocentius, dkk. "The Influence of Brand Awareness, Brand Image, and Brand Trust on Brand Loyalty." Journal Manajemen, Volume 26, Nomor 3 (2020).

Bulan, T.P.L. "Pengaruh Kualitas Pelayanan dan Harga terhadap Loyalitas Konsumen Pada PT. Tiki Jalur Nugraha Ekakurir Agen Kota Langsa." Jurnal Manajemen dan Keuangan, Volume 5, Nomor 2 (2016).

Denisa, Andrea dan Santoso S. B. “Analisis Pengaruh Kualitas Produk, Kualitas Layanan dan Citra Merek Terhadap Loyalitas Pelanggan (Studi Pada Klinik Kecantikan Cosmetics Semarang).” Diponegoro Journal of Management, Volume 5, Nomor 3 (2016).

Dinawan, M. R. "Analisis Faktor-Faktor yang Mempengaruhi Keputusan Pembelian (Studi Kasus pada Konsumen Yamaha Mio PT Harpindo Jaya Semarang)." Jurnal Sains Pemasaran Indonesia, Volume 9, Nomor 3 (2010).

Dora, Y. M. dan A. Faritzal. "The Use of Halal to Improve the Consumer Loyalty of Cosmetik Products in Bandung City Indonesia." International Journal of Psychosocia Rehabiliation, Volume 24, Nomor 2 (2020).

Fathurrahman, A. dan M. Anggesti. "Pengaruh Gaya Hidup, Label Halal dan Harga Terhadap Keputusan Pembelian Kosmetik (Studi Kasus Pada Produk Safi).” Jurnal Ekonomi Syariah, Volume 6, Nomor 2 (2021).

Ferdinand, Augusty. Metode Penelitian Manajemen. Semarang: BP Universitas Diponegoro, 2014.

Habibah, A. "Analisis Labelisasi Halal, Harga dan Rasa terhadap Keputusan Pembelian Konsumen pada Produk Mie.” Jurnal QIEMA, Volume 6, Nomor 1 (2020).

Harti dan M. I. Iffathurjannah. "Pengaruh Kemanan Makanan, Harga dan Rasa Terhadap Keputusan Pembelian." Jurnal Akuntanbel, Volume 18, Nomor 2 (2021).

Henley, D. Celia, et al. "Label Design: Impact on Millenials' Perceptions of Wine." International Journal of Wine Bussines Research, Volume 20, Nomor 1 (2010).

Hijriah, Nur dan Saleh G. "Pengaruh Label Halal Pada Produk Kosmetik Terhadap Keputusan Pembelian.” Jurnal Ilmu Komunikasi, Volume 3, Nomor 2 (2018).

Ishak, Suraiya, et al. "Cosmetics Purchase Behavior of Educated Millenial Muslim Females." Journal of Islamic Marketing, Volume 11, Nomor 5 (2019).

Jaiyeoba, Haruna, et al. "Halal Certification Mark, Brand Quality and Awareness Do They Influence Buying Decisions of Nigerian Consumers?" Journal of Islamic Marketing, Volume 11, Nomor 6 (2019).

Jannah, E. N., et al. "Pengaruh Kualitas Layanan dan Brand Image Terhadap Loyalitas Melalui Kepuasan Pelanggan Matahari Department Store di Jember." Seminar Nasional Manajemen dan Bisnis Ke -3 (2018). 
Kapferer, J. N. Strategic Brand Management, edisi 5. London: Kogan Page, 2012.

Kotler, P dan G. Amstrong. Principles of Marketing, edisi 14. New Jersey: Pearson Education, 2014.

Kotler, P dan K. Keller. Marketing Management, edisi 14. United States of America: Courier/Kendallville, 2012.

Lubis, N. I. "Analisis Loyalitas Konsumen Produk Berlabel Halal.” Jurnal AL-QARDH, Volume 4, Nomor 1 (2019).

Mohezar, S., et al. "Halal Cosmetics Adopotion Among Young Muslim Consumers in Malaysia Religisity Concern." GJAT, Volume 6, Nomor 1 (2016).

Odzemir, Sena, et al. "The Effect of Trust and Peer Influence on Coroporate Brand-Consumer Relationship and Consumer Loyalty." Journal of Business Research, Volume 117, Nomor 37 (2020).

Pangalila, Paulus. A., et al. "Pengaruh Kualitas Pelayanan dan Harga terhadap Loyalitas Pelanggan Pengguna Aplikasi Gojek." Jurnal EMBA, Volume 6, Nomor 4 (2018).

Priyatno, Duwi. SPSS Panduan Mudah Olah Data Bagi Mahasiswa dan Umum. Yogyakarta: Penerbit ANDI, 2018.

Ramlan dan Nahrowi. "Sertifikasi Halal Sebagai Penerapan Etika Bisnis Islami dalam Upaya Perlindungan Bagi Konsumen Muslim.” Ahkam Jurnal Ilmu Syariah, Volume 17, Nomor 1 (2015).

Rusandy, Deby. S. "Pengaruh Brand Image Terhadap Loyalitas Pelanggan yang Dimediasi Kepuasan Pelanggan pada Rumah Makan Titin Trenggalek." Jurnal Riset Inspirasi Manajemen dan Kewirausahaan, Volume 2, Nomor 1 (2018).

Saputi, O. B. dan N. Huda. "Pengaruh Informasi Covid-19 Melaui Media Sosial Terhadap Perilaku Konsumen." Human Falah, Volume 7, Nomor 2 (2020).

Schiffman, Leon G. dan J. Wisenblit. Consumer Behavior, edisi 11. United States of America: Courier Kendallville, 2015.

Sembiring, Inka Janita, et al. "Pengaruh Kualitas Produk dan Kualitas Pelayanan Terhadap Kepuasan Pelanggan dalam Membentuk Loyalitas Pelanggan (Studi Pada Pelanggan McDonalds MT. Haryono Malang).” Jurnal Administrasi Bisnis, Volume 15, Nomor 1 (2014).

Shamma, H. M. dan S. S. Hassan. "Impact of CSR Perception on Brand Image, Brand Attitude, and Buying Willingness: A Study of a Global Café." International Journal of Marketing Studies, Volume 6, Nomor 6 (2014).

Sudaryanto, et al. "Impact of Culture, Brand Image and Price on Buying Decisions: Evidence from East Java, Indonesia." Journal Innovative Marketing, Volume 17, Nomor 1 (2021).

Sugibayashi, Kenji, et al. Halal Cosmetics: A Review on Ingredients, Production, and Testing Methods." Journal Cosmetics, Volume 6, Nomor 37 (2019).

Sugiyono. Metode Penelitian Kuantitatif, Kualitatif, dan R\&D. Bandung: CV. Alfabeta, 2013. Tjiptono, F dan A. Diana. Pemasaran. Yogyakarta: Penerbit ANDI, 2019.

Tjiptono, Fandy. Strategi Pemasaran: Prinsip dan Penerapan. Yogyakarta: Penerbit ANDI, 2019.

Utami, W. B. "Pengaruh Label Halal Terhadap Keputusan Membeli (Survei pada Pembeli 
Produk Kosmetik Wardah di Outlet Wardah Griya Muslim An-nisa Yogyakarta)." Skripsi--Universitas Islam Negeri Sunan Kalijaga, 2013.

Yunaida, E. "Pengaruh Brand Image (Citra Nerek) Terhadap Loyalitas Konsumen Produk Oil Pelumas Evalube di Kota Langsa." Jurnal Manajemen dan Keuangan, Volume 6, Nomor 2 (2017). 